\title{
Reliability and Validity Testing of Modified Structured Wellness Questionnaire for Monitoring the Wellness Perception of University Students
}

\author{
Jaiyesimi Boluwaji Gbenga ${ }^{1}$ \\ ${ }^{1}$ Afe Babalola University [E-mail: dredeemed4christ@gmail.com]
}

\begin{abstract}
Wellness on a general scale is a major global concern as it is perpendicular to achieving monumental success in a drive towards global health challenges. The health status and wellbeing of university students should be major concern as they constitute young adolescent population and are prone to risky lifestyle. The objective of this study is to carry out exploratory factor analysis of modified structured wellness questionnaire used by university students in pursuit of healthy living. The study explored the orientation, health perspective and practices of the university students to assess the factor loading of the modified structures questionnaire for extraction, reduction and compression into variables. A 20-item questionnaire was administered to 1030 students from four different colleges of Afe Babalola University. Analyses were performed using SPSS. Principal axis component was conducted on the data and Cronbach Alpha was used to test the internal consistency of the data. The results of factor analysis showed five factors and eliminate five items that loaded below the cut-off points. The factors were drug and alcohol pattern; health belief and finance; selfexpression and social integration; exercise, sleep and food; strength of social circle.
\end{abstract}

Keywords: Principal axis factoring; Wellness; Healthy living

\section{$1 \quad$ Introduction}

The development of comprehensive theoretical model on wellness requires a working elaboration of the concept of well-being. Diener (1984) suggested that any of such elaboration must include at least three components; It should be subjective, reflecting a concern for how the individual views him- or herself; it should include; positive indices of an individual's sentiments toward life as 
opposed to negative ones; and it should be global to encompass all areas of an individual's life. The World Health Organization (WHO) as early as 1947 defined health in terms of wellness as "physical, mental, and social well-being, not merely the absence of disease" (WHO, 1958) and later provided a definition of optimal health as "a state of complete physical, mental, and social well-being and not merely the absence of disease or infirmity" (WHO, 1964). Dunn (1961), who is widely credited as being the "architect" of the modern wellness movement, defined wellness as "an integrated method of functioning which is oriented toward maximizing the potential of which the individual is capable". Hettler (1984), a public health physician and medical educator, proposed a hexagon model that specifies six dimensions of healthy functioning, including physical, emotional, social, intellectual, occupational, and spiritual.

Two paper-and-pencil assessment instruments, the Lifestyle Assessment Questionnaire (National Wellness Institute, 1983) and Testwell (National Wellness Institute, 1983), were developed based on the hexagon model. Hinds (1983), also a university-based health educator, developed the Lifestyle Coping Inventory to help individuals deal with stress management and health promotion. Ragheb (1993) noted that there is a "strong and growing demand for a wellness measure, valid and reliable, to assist practitioners and scientists". Kulbok and Baldwin (1992), following a concept analysis of preventive health behaviour and a review of the goals of Healthy People 2000 (U.S. Department of Health and Human Services, 1990), also concluded that "reliable and valid measures of the many dimensions of health behaviour in general, and of health promoting behaviour specifically" are clearly needed. Because wellness is "an observable and measurable behaviour" (Palombi, 1992), the development of such measures is indeed possible.

University students represent the future of families, communities, and countries. The period of university education is a highly sensitive transformative period where behavioural modification and life choices are significantly made. Eisenberg, Gollust, Golberstein, and Hefner (2007), also stressed that university is a period of responsibility for choices and lifestyle practices, where students are exposed to the challenges of young adulthood and also tackle the mental and social issues of students' life. Several factors have been identified to be responsible for the moral decadence and unhealthy lifestyle practices among the students in higher institution of learning ranging from peer group influence, internet vices to parental neglect.

Walid et al (2013) in their study stressed that many college students live far from home, escalating their susceptibility to initiating smoking and/or excessive alcohol consumption. Furthermore, university students have more health complaints than their working counterparts, but do not seek help for these problems. Therefore these characteristics underscore the importance of physical and psychological/mental well-being of university students, particularly that 
their health/well-being might be 'worse off' than that of the general population (Stock et al, 2003). This study seek develop standardized instrument concise enough to meet the need of assessing the health and wellness status of university at a glance or in no time.

\section{$2 \quad$ Methodology}

\subsection{Population, sample and sampling techniques}

Afe Babalola University undergraduate students solely formed the population for the study. The sample was drawn from five existing colleges of the university (Social and Management Sciences, Law, Engineering, Sciences, Medical and Health Sciences). The sample size for the study comprises 591 male $(57.3 \%)$ and 440 female $(42.7 \%)$ in total of 1031 students. The sampling techniques used for the study were stratified and simple random sampling techniques. Stratified sampling technique was used to select $20 \%$ of the total population from each college: Social and Management Sciences had 263 students (25.5\%); Law had 180 students (17.5\%); Engineering had 219 students (21.2\%); Sciences had 142 students (13.8\%) and Medical and Health Sciences had 227 students $(22.0 \%)$. Simple random sampling technique was used to randomly select students in each college.

\subsection{Instrument and procedures}

The instrument is intended to monitor the wellness perception of university students (Wellness Perception Questionnaire, WPQ). Primary data was gathered using a modified 20-item structured wellness questionnaire. The instrument comprised five different subscales, as follows; (a) drug and alcohol pattern (Q1, Q2, Q3) (b) health, belief and finance (Q4, Q5, Q6, Q7, Q8) (c) public speaking and social integration $(\mathrm{Q} 10, \mathrm{Q} 11, \mathrm{Q} 12)(\mathrm{d})$ sleep and meal pattern (Q14, Q15) (e) strength of social circle (Q18, Q19). Q9, Q13, Q16, Q17 and Q20 were extracted from the scale due to low factor loading (>.40 cut off point). The five subscales are the results of the exploratory factor analysis. The questionnaire assessed the respondents on a 5-point scale with 1=Almost Always and 5= Never. Questionnaires were administered to the respondents with the aid of research assistants who are were well tutored on the significance of the research. Respondents were assured of anonymity and confidentiality of the provided personal details and that their participation in the research is voluntary. 


\subsection{Data analysis}

The returned questionnaire were subjected to editing and coding for input into the Statistical Programme for the Social Sciences (SPSS - version 17). Descriptive statistics were calculated to present the basic characteristics of the demographic data. In addition, exploratory factor analysis was performed on the 20 -items. Prior to this, the appropriateness of factorability on the data set was established using the Kaiser-Meyer-Olkin (KMO) measure of sampling adequacy (MSA) and the Bartlett's Test Sphericity. The Bartlett's Test of Sphericity was $3654.53(\mathrm{DF}=190)$ at an observed significance level of 0.0000 thus rejecting the hypotheses that the population correlation matrix is an identity matrix, i.e. with zero correlations. The KMO measure of sampling adequacy provides an index between 0 and 1 of the proportion of variance among the items that might be indicative of latent common factors. Kaiser (1974) considered 0.796 (approx. 0.80) as good KMO for factor analysis. The criterion of eigenvalue or characteristic root (Eigenvalue) $\geq 1$ was used for defining the number of the factors that were kept (Kaiser, 1960, Sharma, 1996, Hair et al., 1995).

\subsection{Reliability}

Table 1 on reliability statistics showed the value of the coefficient of Cronbach for the research scale $(0.781=78.1 \%)$. This is very close to the $80 \%$ which is an extra good value for the internal consequence of the conceptual construction of the investigated scale (Anastasiadou, 2010; Nouris, 2006). The questionnaire reliability (internal consistency) was possible by Cronbach's $\alpha$ (Cronbach, 1984), which is considered to be the most important reliability index and is based on the number of the variables/items of the questionnaire, as well as on the correlations between the variables (Nunnally and Jun, 1978).

Table 1: Reliability of Wellness Perception Questionnaire

\begin{tabular}{lll}
\hline Cronbach's Alpha & Cronbach's Alpha Based on Standardized Items & N of Items \\
\hline .771 & .781 & 20 \\
\hline
\end{tabular}

Table 2 on Scale Statistics revealed the scores that are related to the scale's entirety, which presents a mean of the class of 45.32 and a standard deviation of the class of 10.960 units.

Table 2: Scale Statistics of Wellness Perception Questionnaire (WPQ)

\begin{tabular}{llll}
\hline Mean & Variance & Std. Deviation & $\mathrm{N}$ of Items \\
\hline 45.32 & 120.130 & 10.960 & 20 \\
\hline
\end{tabular}


Table 3: Item-Total Statistics

\begin{tabular}{|c|c|c|c|c|}
\hline Item & $\begin{array}{l}\text { Scale Mean } \\
\text { if Item } \\
\text { Deleted }\end{array}$ & $\begin{array}{l}\text { Scale Variance } \\
\text { if Item } \\
\text { Deleted }\end{array}$ & $\begin{array}{l}\text { Corrected } \\
\text { Item-Total } \\
\text { Correlation }\end{array}$ & $\begin{array}{l}\text { Cronbach's } \\
\text { Alpha if Item } \\
\text { Deleted }\end{array}$ \\
\hline 1. Do you drink fewer than 5 alcoholic drinks a week? & 43.26 & 109.212 & .384 & .758 \\
\hline 3. Do you drink fewer than 3 caffeine drinks a day? & 43.06 & 109.997 & .392 & .758 \\
\hline 4. Are you in good health & 43.28 & 109.407 & .380 & .758 \\
\hline 5. Do you get strength from your religious or spiritual beliefs? & 42.56 & 108.007 & .368 & .759 \\
\hline 8. Do you take quiet time for yourself during the day? & 43.28 & 113.132 & .248 & .767 \\
\hline 9. Are you the appropriate weigh for your height? & 43.37 & 111.384 & .319 & .762 \\
\hline 10. Are you able to speak openly about your feelings when angry? & 43.46 & 114.706 & .181 & .770 \\
\hline $\begin{array}{l}\text { 11. Do you have regular conversation with your housemates about } \\
\text { domestic problems? }\end{array}$ & 42.56 & 111.332 & .248 & .767 \\
\hline 12. Do you do something fun at least once a week? & 43.20 & 108.426 & .425 & .756 \\
\hline 17. Do you give and receive affection regularly? & 43.02 & 108.712 & .385 & .758 \\
\hline $\begin{array}{l}\text { 18. Do you have at least } 1 \text { friend in the school or at home on whom } \\
\text { you can rely? }\end{array}$ & 43.12 & 110.919 & .371 & .760 \\
\hline $\begin{array}{l}\text { 19. Do you have at least } 1 \text { friend in whom you confide about personal } \\
\text { matters? }\end{array}$ & 42.64 & 108.660 & .287 & .766 \\
\hline 20. Do you have a network of friends and acquaintances? & 43.07 & 109.800 & .347 & .760 \\
\hline
\end{tabular}


Table 3 on Item-Total Statistics of WPQ, the scale mean of item deleted are as follows 43.26, 42.74, 43.06, 43.28, 42.56, 42.78, 42.89, 43.28, 43.37, 43.46, $42.56,43.2,43.16,43.44,42.96,43.21,43.02,43.12,42.64,43.07$ units. In the fourth column the number $0.384,0.37,0.392,0.38,0.368,0.283,0.287,0.248$, $0.319,0.181,0.248,0.425,0.423,0.295,0.38,0.389,0.385,0.371,0.287,0.347$ means that the item 1-20 have Pearson coefficient of correlation of the class $38.4 \%, 37 \%, 39.2 \%, 38 \%, 36.8 \%, 28.3 \%, 28.7 \%, 24.8 \%, 31.9 \%, 18.1 \%$, $24.8 \%, 42.5 \%, 29.5 \%, 38 \%, 38.9 \%, 38.5 \%, 37.1 \%, 28.7 \%$ and $34.7 \%$.

\subsection{Sample Sufficiency Test and Sphericity Test}

Table 4 revealed the sample sufficiency index KMO by Kaiser-Meyer-Olkin, which compares the sizes of the observed correlation coefficients to the sizes of the partial correlation coefficients for the sum of analysis variables. The test of sphericity by the Bartlett test is rejected on a level of statistical significance $\mathrm{p}<0.005$ (Chi-Square $=3654.525, \mathrm{p}=0.000$ ). Consequently, the coefficients are not all zero, so that the second acceptance of factor analysis is satisfied. As a result, both acceptances for the conduct of factor analysis are satisfied.

Table 4: KMO and Bartlett's Test

\begin{tabular}{lll}
\hline Kaiser-Meyer-Olkin Measure of Sampling Adequacy. & .796 \\
\hline Bartlett's Test of Sphericity & Approx. Chi-Square & 3654.525 \\
& df & 190 \\
& Sig. & .000 \\
\hline
\end{tabular}

\subsection{The Scree Plot Graph}

The scree test (Figure 1) produces the following graph, which proceeded to a graphic representation of eigenvalues and showed the determination of the number of the essential factorial axis. 


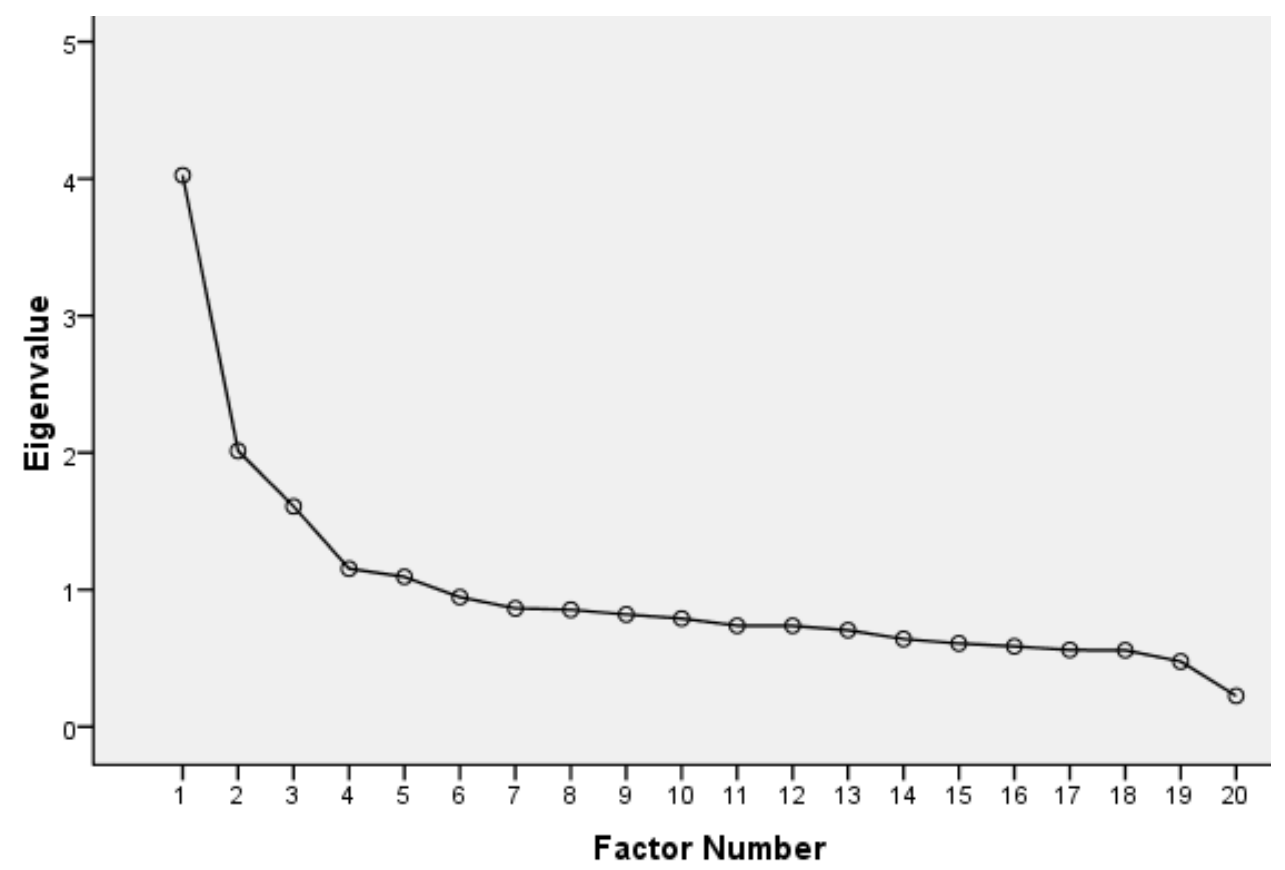

\section{Figure 1: Scree Plot}

The above graph shows a distinct break up to the fifth factor, whereas, after the fourth one, it follows a linear part of the eigenvalue curve. So, taking into consideration eigenvalues, which are higher than 1 for the five factors (4.026, $2.014,1.609,1.153$, and 1 . for the $1 \mathrm{st}, 2 \mathrm{nd}, 3 \mathrm{rd}, 4$ th and 5 th respectively), the data can be said to interpret satisfactorily.

\subsection{Principal Axis Factoring}

Principal axis factoring showed five components, which jointly attributed to the $49.479 \%$ of the total variance, and which are separately described afterwards. The internal reliability coefficient Cronbach's $\alpha$ is significantly high and equal to $78.1 \%$ for the whole questions, and that's why the 20 -question scale was considered significantly reliable in the sense of internal consistency. The reliability coefficient (Cronbach's a) is statistically significant and equal to $74.3 \%, 56.4 \%, 55.7 \%, 55.2 \%, 61.3 \%$ for the 1 st, 2 nd, 3rd 4th and 5th factorial axis respectively. 
Table 5: Principal Axis Factoring on Health and Wellness Questionnaire

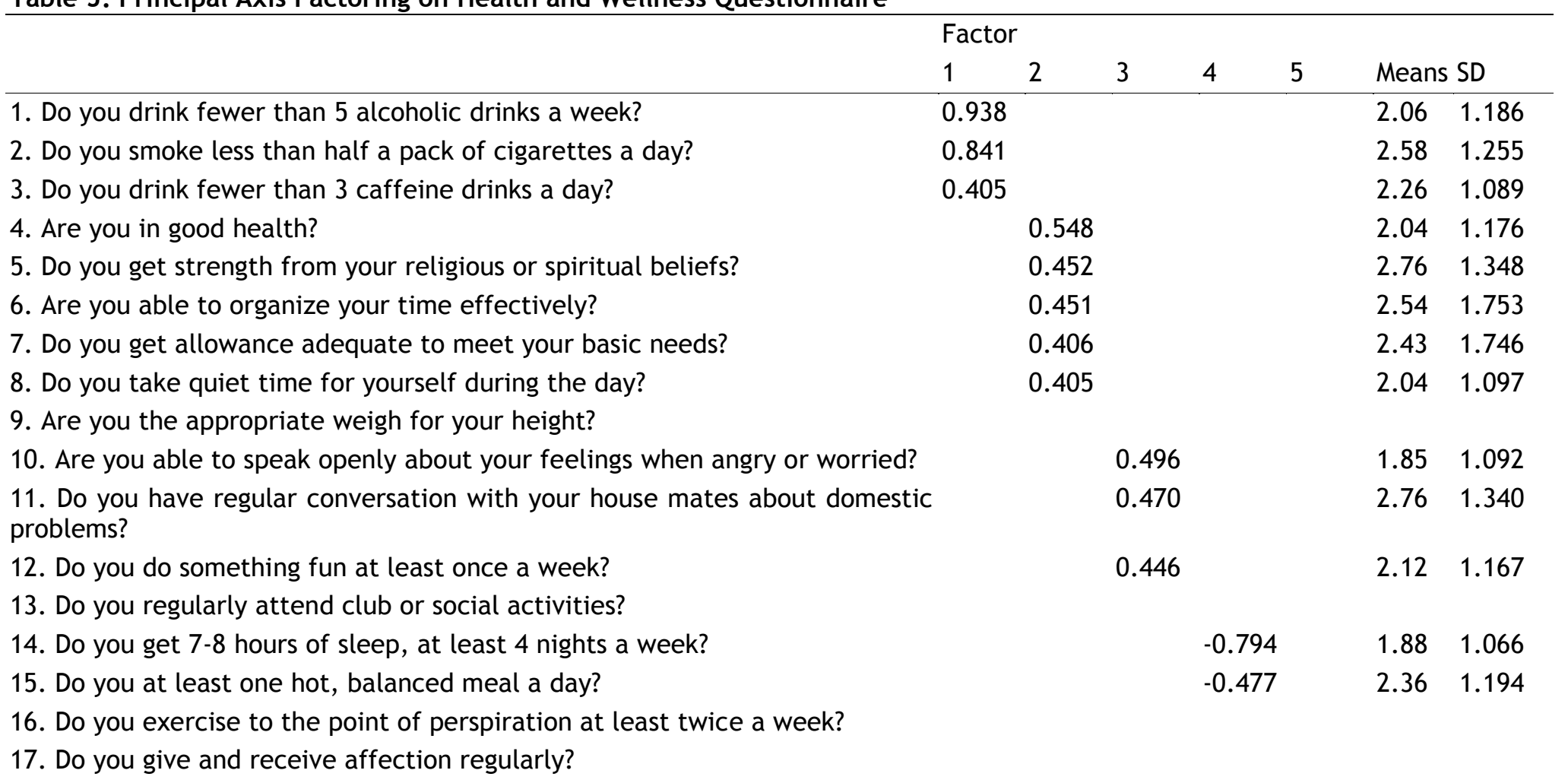


18. Do you have at least 1 friend in the school or at home on whom you can rely?

19. Do you have at least 1 friend in whom you confide about personal matters?

$-0.4672 .68 \quad 1.529$

20. Do you have a network of friends and acquaintances?

$\%$ of variance explained

$20.12910 .0698 .044 \quad 5.767 \quad 5.471$

Cumulative \%

Eigenvalues

Cronbach Alpha

Total Cronbach Alpha

20.12930 .19738 .24244 .00849 .479

$\begin{array}{lllll}4.026 & 2.014 & 1.609 & 1.153 & 1.094\end{array}$

$\begin{array}{lllll}0 & 0.564 & 0.557 & 0 & 0.613\end{array}$

Kaiser-Meyer-Olkin Measure of Sampling Adequacy $=.796$

$.743 \quad .552$
.781

Bartlett's Test of Sphericity: $X 2=3654.525, d f=190, p=0.000$

Extraction Method: Principal Axis Factoring.

Rotation Method: Oblimin with Kaiser Normalization.

a. Rotation converged in 23 iterations. 
Table 5 presents the components and the factor loadings produced after Principal axis factoring. More specifically, based on wellness perception as presented by the factor analysis, Q1, Q2 and 3 particularly with high loadings $(0.938,0.841,0.405)$ load mainly on the first axis-factor $\mathrm{F} 1$, with eigenvalue 4.026, which explains, following Oblimin rotation, $20.129 \%$ of the total dispersion. Factor (F1) represents drug and alcohol pattern of the university student in relation to their wellness status and perception. Reliability of the first factor is $a=0.743$, which is particularly satisfactory.

Q4, Q5, Q6, Q7 and Q8 particularly with high loadings $(0.548,0.452,0.451$, $0.406,0.405$ ) on the second factor (F2), with eigenvalue 2.014, which explains $10.069 \%$ of the total dispersion. The second factor consists of the statements on the health belief and finance of the students in relation to their wellness status and perception. The reliability of the second factor is $a=0.564$, which is satisfactory.

Q10, Q11 and Q12 particularly with high loadings $(0.496,0.470,0.446)$ on the third factor (F3) with eigenvalue 1.609 , which explains $8.044 \%$ of the total dispersion. The third factor (F3) consists of the statements on self-expression and social integration. The reliability of the third factor is $a=0.557$, which is satisfactory.

Q14 and Q15 particularly with high loadings (-0.794, -0.477) are on the fourth factor (F4) with eigenvalue 1.153 , which explains $5.767 \%$ of the total dispersion. The fourth factor (F4), consists of the statements on the sleep and meal pattern. The reliability of the third factor is $a=0.552$, which is satisfactory.

The fifth and final factor (F5) with eigenvalue 1.094, with quite high loadings $(-0.619,-0.467)$ which explains $5.471 \%$ of the total data inactivity, is constructed and interpreted by questions Q18 and Q19. The fifth factor consists of variables on the strength of social circle. The reliability of the fourth factor is $a=0.613$, which is satisfactory.

Q9 on "are you the appropriate weight for your height", Q13 on "do you regularly attend club or social activities", Q16 on "do you exercise to the point of perspiration at least twice a week", Q17 on "do you give and receive affection regularly" and Q20 on do you have a network of friends and acquaintances were extracted from the instrument due to low factor loading (cut off point $>.40$ ). 

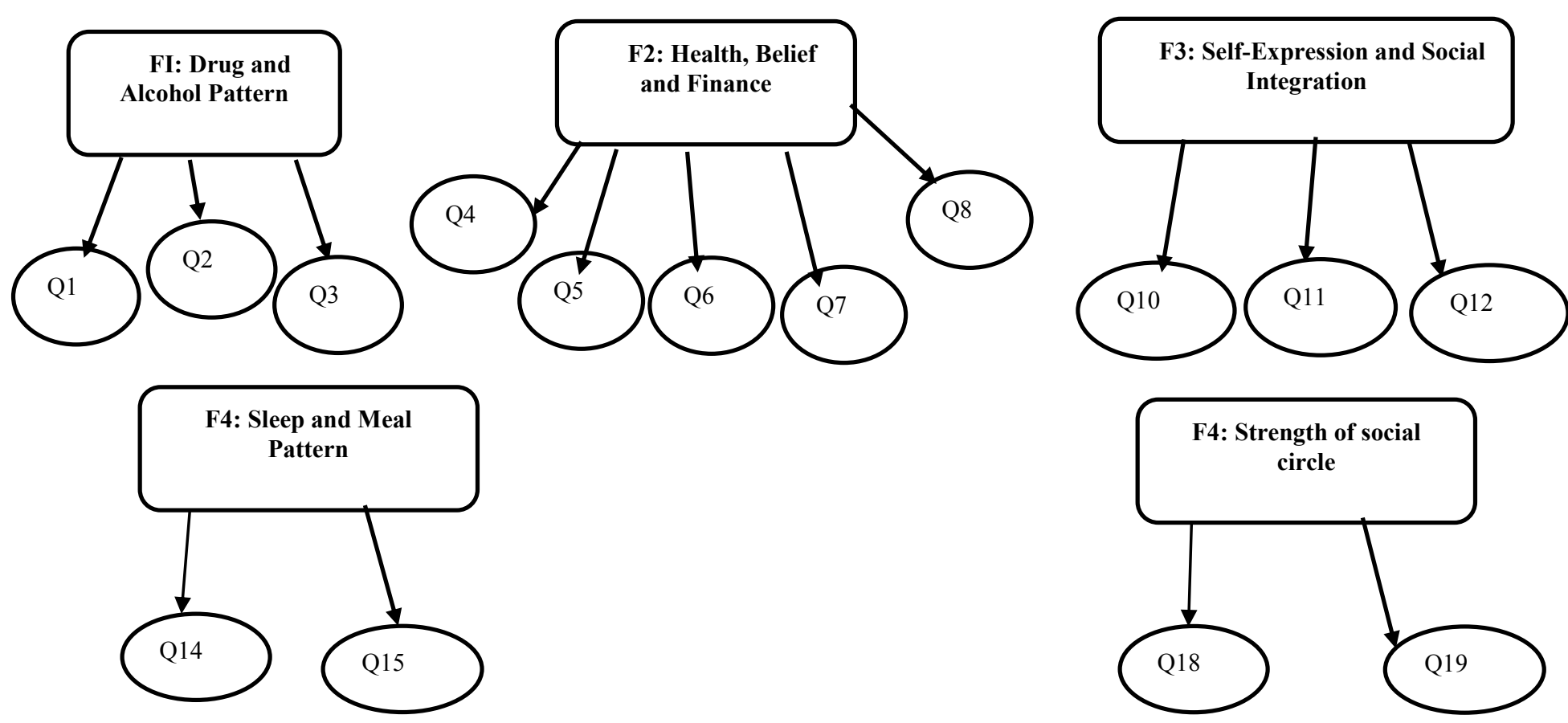

Figure 2: Schematic Diagram on the Summary of Exploratory Factor Analysis Variables 


\section{Wellness Perception Questionnaire (WPQ) variables and items after extraction}

\section{FI: Drug and Alcohol Pattern}

Q1: Do you drink fewer than 5 alcoholic drinks a week?

Q2: Do you smoke less than half a pack of cigarettes a day?

Q3: Do you drink fewer than 3 caffeine drinks a day?

\section{F2: Health, Belief and Finance}

Q4: Are you in good health?

Q5: Do you get strength from your religious or spiritual belief?

Q6: Are you able to organize your time effectively?

Q7: Do you get allowance adequate to meet your basic needs?

Q8: Do you take quiet time for yourself during the day?

\section{F3: Self-Expression and Social Integration}

Q10: Are you able to speak openly about your feelings when angry or worried?

Q11: Do you have regular conversation with your house mates about domestic problems?

Q12: Do you do something fun at least once a week?

\section{F4: Sleep and Meal Pattern}

Q14: Do you get 7-8 hours of sleep, at least 4 nights a week?

Q15: Do you at least one hot, balanced meal a day?

\section{F5: Strength of Social Circle}

Q18: Do you have at least 1 friend in the school or at home on whom you can rely?

Q19: Do you have at least 1 friend in whom you confide about personal matters?

\section{Conclusion and Recommendation}

Therefore, a model of five factors has been created after the examination of the validity and reliability of the wellness perception of the university students on the Wellness Perception Questionnaire (WPQ). The WPQ is a 15 item questionnaire that can be adopted to monitor the wellness status and perception of university students or young adolescents in pursuit of healthy living. Principal axis factoring made it possible to have five subscale/variables of WPQ namely: Drug and Alcohol Pattern (DAP), Health, Belief and Finance (HBF), Public Speaking and Social Integration (PSSI), Sleep and Meal Pattern (SMP) and Strength of Social Circle (SSC). A total of five items were deleted from the health and wellness questionnaire due to very low factor loading, to 
produce the Wellness Perception Scale (WPQ). It appears to hold considerable promise as a research instrument for identifying unexplored dimension of wellness as the concept is growing beyond the scope of current research studies as result of emerging wellness related issues. A qualitative research can complement and enrich this quantitative research study to further enrich and enliven the effort invested into this research work.

As a result of the study, the following are therefore recommended:

1. There is need for the educational stakeholders and policy makers for higher institution of learning to pay more clinical attention to the health and wellness needs of the students and other staff members of the academic community;

2. There is need to monitor and regulate the business and consumption rate of drug and alcohol in the academic community and increase the awareness level of health implication of drug and alcohol use and abuse;

3. There is need for enhanced financial support for the outstanding and lessprivileged students in the academic communities in form of bursaries, financial loan scheme. Scholarship, cumulative grade point awards, entrepreneurial awards and so on, as the study has revealed that health, belief and finance could play a significant role in the wellness perception of university students;

4. The academic community should also play supportive role to the student in the area of public speaking and social integration in the right direction in such a way that wrong ideas are suppressed for right ideas to emerge. Students should not be silenced but guided in the mode of expression of their ideas and/or grievances.

5. There is need for academic community to employ every means of health promotion and awareness to foster healthy eating practices among the staff and students.

\section{References}

Anastasiadou, S. (2006).). Factorial validity evaluation of a measurement through principal components analysis and implicative statistical analysis. In D.X.Xatzidimou, K. Mpikos, P.A. Stravakou, \& K.D. Xatzidimou (eds), 5th Hellenic Conference of Pedagogy (pp. 341-348). Thessalonika: Conference of Pedagogy Company.

Cronbach, L. J. (1984). Essentials of psychological testing (4th Ed.). New York: Harper \& Row.

Diener, E. (1984). Subjective well-being. Psychological Bulletin, 95,542-575.

Dunn, H. L. (1961). High-level wellness. Arlington, VA: Beatty. 
Eisenberg D, Gollust SE, Golberstein E, Hefner JL. (2007) Prevalence and correlates of depression, anxiety, and suicidality among university students. Am J Orthopsychiatry. (77) 534-542.

Hair, J. A. (1995). . Multivariate Data Analysis with Readings, p.373. . USA: Prentice-Hall International, Inc.

Hettler, W. (1984). Wellness: Encouraging a lifetime pursuit of excellence. . Health Values: Achieving High Level Wellness, 8, 13-17.

Hinds, W. C. (1983). Personal paradigm shift: A lifestyle intervention approach to health care management. East Lansing: Michigan State University.

Institute, N. W. (1983). Testwell. . Stevens Point, WI: Author.

Kaiser, H. ((1974). An index of factorial simplicity. Psychometrika, 39, 31-36.

Kaiser, H. F. ((1960).). The application of electronic computers to factors analysis. Educational and Psychological Measurement, 20, 141-151.

Kulbok, P. A. (1992). From preventive health behaviour to health promotion: Advanced Nursing Science, 14, 50-64.

Nunnally, C. J. ((1978). Psychometric Theory. . New York: McGraw Hill Book Co.

Organization, W. H. (1958). Constitution of the World Health Organization. Annex, Geneva, Switzerland: Author.

Organization, W. H. (1964). Basic documents (15th Ed.). Geneva, Switzerland: Author.

Palombi, B. J. (1992). Psychometric properties of wellness instruments. , . Journal of Counselling \& Development, 71, 221-225.

Ragheb, M. G. (1993). Leisure and perceived wellness: A field investigation. Leisure Sciences, 15, 13-24.

Services, U. D. (1990). Healthy people 2000: National health promotion and disease prevention objectives. Washington, DC: U.S. Government Printing Office: Author.

Sharma, S. (1996). Applied Multivariate Techniques. USA: John Willey \& Sons, Inc.

Stock C, Kücük N, Miseviciene I, Guillén-Grima F, Petkeviciene J, AguinagaOntoso I, et al. (2013). Differences in health complaints between university students from three European countries. Prev Med. (37)535-543.

Walid El Ansari, Shokria Labeeb, Lawrence Moseley, Safaa Kotb,and Amira El-Houfy (2013). Physical and Psychological Well-being of University Students: Survey of Eleven Faculties in Egypt. Int J Prev Med. 4(3): 293310. 